\title{
Staphylococci in septic fingers
}

\author{
O. WESLEY-JAMES ${ }^{1}$ AND V. G. ALDER
}

From the Department of Pathology, United Bristol Hospitals

SYNOPSIS The phage patterns of 123 cultures of Staphylococcus aureus isolated from septic fingerso were compared with 124 strains isolated from the noses of healthy volunteers. It was found thato strains with certain phage patterns were comparatively numerous in septic fingers, and that the $\dot{-}_{\triangle}$ lesions caused by them tended to be exceptionally severe.

Some strains of $S$. aureus are very prone to cause primary skin infections. Notably are those with phage patterns 80 (Rountree and Freeman, 1955), 52A/79 (Alder, Gillespie, and Thompson, 1955) and some phage group II strains (Roodyn, 1954). Moreover, the infections caused by these strains (particularly phage type 80 ) are often exceptionally severe.

This investigation was undertaken to see whether a similar association existed among staphylococci causing septic fingers.

\section{METHODS}

The patients were seen in the Casualty Department. None had been given antibiotics. Those whose lesions had not localized and from which pus could not be examined bacteriologically, were excluded. The series of 138 patients was otherwise unselected.

The lesions were classified as to anatomical site, and their severity was assessed by the criteria shown in Table II.

Contact with hospitals during the preceding three months was noted, and included attendance at outpatient clinics and visits to relatives in the wards.

Pus taken at the time of incision was cultured aerobically on blood agar plates. Swabs were also taken from the patients' noses, and for comparison from the noses of 300 healthy volunteers resident in Bristol (238 blood donors and 62 patients with minor traumatic conditions attending the Casualty Department for the first time). None of the volunteers had attended hospitals in the 12 months before the investigation.

The bacteriological methods were those of Alder et al. (1955). Phage typing was carried out with the basic set of Colindale phages (Anderson and Williams, 1956).

\section{RESULTS}

The anatomical distribution of the lesions is shown in Table I. Cultures of Staph. aureus were obtained

\footnotetext{
1 Present address: Hamilton Health Association, Hamilton, Ontario, Canada.
}

from 123 lesions. Of the remaining 15 , three were $\frac{\text { ? }}{-}$ sterile and 12 yielded a variety of organisms other $\vec{c}$ than Staph. aureus.

All of the 24 dorsal carbuncles seen were pure staphylococcal infections, this being in accordance with the fact that a dorsal carbuncle on the finger is $\overrightarrow{0}$ no different from carbuncles in other sites and iso caused solely by Staph. aureus.

\section{TABLE I}

ANATOMICAL DISTRIBUTION OF THE 138 FINGER LESIONS

\begin{tabular}{|c|c|c|c|c|c|c|}
\hline $\begin{array}{l}\text { Causative } \\
\text { Organism }\end{array}$ & Total & $\begin{array}{l}\text { Pulp } \\
\text { Space } \\
\text { Infections }\end{array}$ & $\begin{array}{l}\text { Apical } \\
\text { Compartment } \\
\text { Abscesses }\end{array}$ & $\begin{array}{l}\text { Dorsal } \\
\text { t Car- } \\
\text { buncles }\end{array}$ & $\begin{array}{l}\text { Sub- } \\
\text { cutaneous } \\
\text { Abscesses }\end{array}$ & $\begin{array}{l}\text { Paron } \\
\text { ychia }\end{array}$ \\
\hline Staph aureus & 123 & 19 & 11 & 24 & 23 & 46 \\
\hline $\begin{array}{l}\text { Other } \\
\text { organisms }\end{array}$ & 12 & 1 & 2 & 0 & 5 & \\
\hline $\begin{array}{l}\text { No organisms } \\
\text { isolated }\end{array}$ & is & 0 & 0 & 0 & 1 & 2 \\
\hline Totals & 138 & 20 & 13 & 24 & 29 & 52 \\
\hline
\end{tabular}

SOURCES AND PHAGE PATTERNS OF THE STAPHYLOCOCCI Table II shows the phage patterns of the staphy lococci isolated from all sources. By comparison withp the staphylococci from healthy volunteers, the lesions: yielded proportionately more group I strains with the phage patterns 80 and 52A/79 (but not other group I strains). Group II strains which were insensi tive to phage $3 \mathrm{~A}$, and the miscellaneous strains were also slightly more numerous in the lesions. The phage patterns of strains from patients' noses were similarly distributed to those from the lesions. It thus appeare that septic fingers were sometimes caused by staphy? lococci from the patients' carrier sites, as has been demonstrated with simple furunculosis (Roodyn 1954; Tulloch, 1954; Tulloch, Alder, and Gillespie? 1960).

Phage group II strains which were lysed by phage $3 \mathrm{~A}$ were not infrequently isolated from healthy noses 
TABLE II

PHAGE TYPES AND CLINICAL SEVERITY OF THE STAPHYLOCOCCI FROM SEPTIC FINGERS

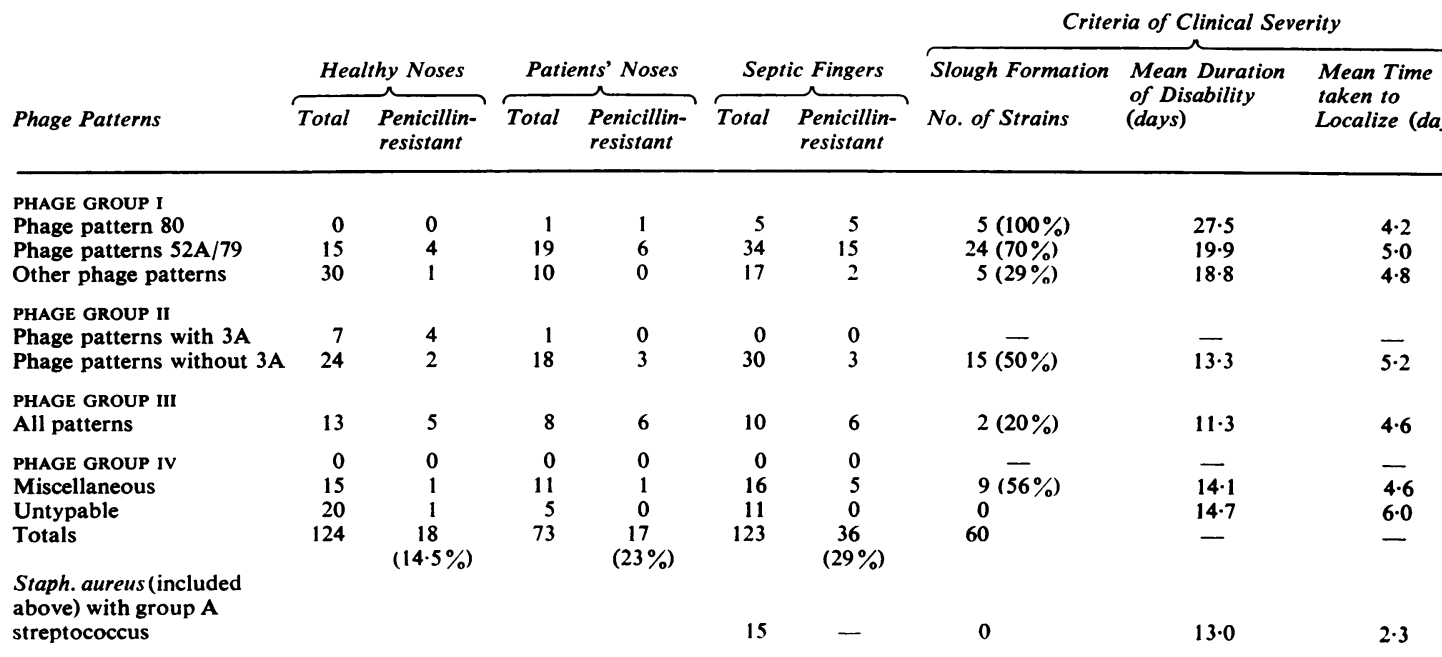

but never from septic fingers. This finding was similar to that of Alder (1956) in strains from furunculosis.

There were only 10 septic finger strains in phage group III, and together they possessed nine different phage patterns; no strains reacted with phage 42D. There were 16 patterns in the miscellaneous group and 11 strains were untypable.

PHAGE TYPeS AND Clinical SEverity The lesions caused by certain strains of staphylococci tended to be exceptionally severe. The more virulent strains were those which were found comparatively often in septic fingers as compared with healthy noses, e.g., type 80 and 52A/79, phage group II strains insensitive to $3 \mathrm{~A}$, and the miscellaneous group (Table II). The association between sloughing and prolonged disability on the one hand and phage pattern on the other was particularly well marked with the phage group I strains. The severest lesions were caused by the type 80 staphylococci in accordance with what has been found with furunculosis (Rountree and Freeman, 1955; Gillespie and Alder, 1957), and patients experienced considerable malaise. It was also of interest that of the 46 paronychias in the series, the only one to form a slough was caused by the only type 80 strain isolated from a paronychia.

The presence of a combined infection with a group A streptococcus apparently shortened the clinical course, resulting in early localization (Table II).

RESISTANCE TO ANTIBIOTICS The penicillin resistance of the different phage types is shown in Table II. $8^{*}$
Thirty-six (29\%) of the 123 strains from septic fingers were resistant to penicillin compared with only $18(14.5 \%)$ of the 124 healthy nose strains. This difference could be accounted for by the greater number of type $80,52 \mathrm{~A} / 79$, and 'miscellaneous' strains in the septic finger group. All five type 80 staphylococci were resistant to penicillin, and three of these were resistant to other antibiotics as well.

Contact with hospitals was significantly associated with the presence of penicillin-resistant staphylococci in lesions. Of the 25 patients with hospital contacts, $16(64 \%)$ were infected with penicillin-resistant staphylococci compared with $20(20.4 \%)$ of the 98 other patients.

\section{DISCUSSION}

The assessment of virulence by the clinical severity of lesions presents difficulties, but in the present series certain strains, notably those with phage patterns 80 and 52A/79, together with some group II strains, were undoubtedly associated with unusually severe lesions.

The two most reliable measures of clinical severity were the duration of disability and the percentage of lesions which led to sloughing. The formation of a slough in a septic finger is therefore sometimes related to the properties of the causal staphylococcus and not only, as is sometimes taught, to faulty or delayed treatment. In the present series early sloughing was often a feature of the more severe lesions, particularly those caused by staphylococci with phage types $\mathbf{8 0}$ 
and $52 \mathrm{~A} / 79$, and evidently had nothing to do with the treatment.

We wish to thank Mr. H. K. Bourns, surgeon in charge of the Casualty Department, Bristol Royal Infirmary, for his encouragement and permission to treat cases under his care; Dr. W. A. Gillespie for his help and criticism; and the Board of Governors of the United Bristol Hospitals for financial help to enable this work to be completed.

\section{REFERENCES}

Alder, V. G. (1956). B.Sc. Thesis, Bristol University. Gillespie, W. A., and Thompson, M. E. M. (1955). J. Path. Bact 70, 503.

Anderson, E. S., and Williams, R. E. O. (1956). J. clin. Path., 9, 94. Gillespie, W. A., and Alder, V. G. (1957). Lancet, 1, 632.

Roodyn, L. (1954). Brit. med. J., 2, 1322.

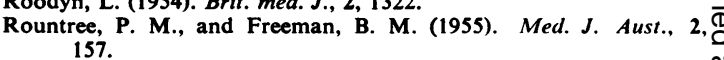

Tulloch, L. G. (1954). Brit. med. J., 2, 912.

$\longrightarrow$, Alder, V. G., and Gillespie, W. A. (1960). Ibid., 2, 354. 